\title{
Keterpenjaraan perempuan dalam ruang kota di dalam Lost in translation (2003) dan The good girl (2002)
}

\author{
ASRI SARASWATI
}

\begin{abstract}
The urban space offers more challenges to the female self. Two motion pictures, Lost in translation (2003) and The good girl (2002), depict the issue of gender and space by conveying the city as prison for the female characters. This article analyses the urban space and argues that in the two movies, the female characters struggle and eventually create meaning in the urban room. Applying feminism and urban geography in analysing the position of female characters within the city, the paper finds that the two films offer their perception on, and solutions to, the imprisonment of women by the urban environment which is stereotypically masculine.
\end{abstract}

KEYWORDS

Gender (gender), ruang (space), kota (city).

"I'm trying to organize a prison break. I'm looking for an accomplice. We'd have to, first, get out of this bar, then the hotel, then the city, and then the country. Are you in or are you out?", demikian gurauan Bob dalam film Lost in translation (2003), film yang disutradarai Sophia Copolla. Lewat kacamata Bob dan Charlotte, dua orang Amerika yang mengunjungi Jepang, penonton disuguhkan keterpenjaraan di tengah ruang Tokyo yang metropolitan. Mereka teralienasi di tengah gaya hidup Tokyo dan menemukan kenyamanan dalam diri satu dengan yang lain. Isu ruang kota dan keterpenjaraan muncul pula dalam The good girl (2002), film karya sutradara Miguel Arteta. Tokoh utamanya yang bernama Justine di awal film berkata, "As a girl you see the world like a giant candy store filled with sweet candy. But one day you look around, you see a prison and you're on a death row. Something's locking you

ASRI SARASWATI adalah pengajar pada Program Studi Inggris, Fakultas Ilmu Pengetahuan Budaya, Universitas Indonesia dengan minat penelitian di bidang psikoanalisis, multikulturalisme, kajian film, dan youth culture. Makalah yang dibawakan antara lain: "Polygamy as a discourse representing Indonesian society" (Ninth International Conference on Social Representation (ICSR), Bali, 30 Juni-5 Juli 2008); "A hybrid language: an analysis on Indonesian commercials" (Sixth ASIA TEFL (Teaching English as a Foreign Language) International Conference, Bali, 1-3 Agustus 2008).

(C) 2009 Fakultas Ilmu Pengetahuan Budaya, Universitas Indonesia 
up". Kata 'prison' yang muncul berulang dalam kedua fim menjadikan kota tak sekedar sebuah ruang modern, melainkan sebuah ruang yang dirasakan dapat memenjarakan.

Dalam kajian budaya, ruang (space) adalah tempat bertarungnya nilai dan kepentingan (Baldwin et al. 2004: 140-141). Ruang urban yang kini lazim kita temui menawarkan tantangan baru terhadap konsep kontestasi tersebut. Dalam Lost in translation dan The good girl, gender turut berperan ketika kedua teks menceritakan pengalaman perempuan dalam ruang urban. Melalui artikel ini, saya berargumen bahwa keterpenjaraan dalam kota di kedua film memiliki hubungan dengan persoalan gender; dan sebagai bentuk perlawanan, kedua film berbicara mengenai ketegangan antara maskulinitas dan femininitas melalui penggambaran ruang kota yang dikuasai oleh nilai dan norma patriarki.

Charlotte dalam Lost in translation adalah istri yang "terpenjara". Ia mengikuti sang suami yang sedang bekerja di Tokyo hingga merasa teralienasi dan kehilangan jati diri di tengah situasi yang ada. Penghiburan hadir melalui tokoh Bob, seorang aktor yang datang ke Tokyo karena pekerjaan. Dalam interaksi mereka, Bob dan Charlotte bertahan dalam ruang kota metropolitan yang hiper-realita dan menciptakan kenyamanan mereka sendiri. Lain lagi dengan Justine, tokoh utama film The good girl, yang menyebut kehidupannya di kota kecilnya sebagai 'penjara'. Ia lelah dengan sang suami, dengan pekerjaannya sebagai penjaga gerai kosmetik, dan rutinitasnya. Justine adalah perempuan tipikal kota kecil di Amerika - menikah dengan pacar SMA dan tidak pernah meninggalkan kota kelahirannya. Konflik beranjak ketika Justine bertemu Holden, lelaki muda yang menawarkannya cinta dan kebebasan.

Fokus artikel ini adalah keterpenjaraan perempuan yang secara metaforik terjadi akibat modernitas ruang kota. Ruang dalam kedua film yang dibahas akan dikaji sebagai ruang sosial yang memiliki dimensi simbolik dan berinteraksi dengan tokoh yang ada di dalamnya. Atribut dan detail pada ruang-ruang yang signifikan akan dicermati dengan menggunakan konsep maskulinitas dan femininitas dalam lingkungan hidup urban yang dipengaruhi kuat oleh nilai dan norma patriarki. Tujuan dari pembahasan ini adalah untuk mengungkap bagaimana tokoh-tokoh perempuan dalam kedua film yang dibahas itu ditempatkan dalam lingkungan urban itu. Sebagai hasil akhir, artikel akan menyimpulkan bagaimana kedua film memberikan pemaknaan berbeda terhadap keterpenjaraan perempuan dalam ruang kota.

\section{KONSEP RUANG DAN GENDER}

Penelitian dalam tulisan ini dilakukan dengan bertolak dari temuan sosiolog Perancis, Henri Lefebvre, yang dituliskan dalam The production of space (1984: 98), yaitu bahwa ruang menggerakkan manusia melalui asosiasi simbolik dan menciptakan hubungan antara ruang itu dan subjek (dalam Mountford 2001: 49). 
Dalam kajian budaya, ruang dilihat lebih dari sekedar lokasi. Ruang adalah ajang praktik sosial yang memiliki makna. Menganalisis sebuah ruang berarti mencermatinya sebagai tempat terjadinya produksi budaya yang melibatkan kekuasaan, pertahanan, dan representasi secara terus-menerus (Baldwin et al. 2004). Kajian geografi budaya melihat ruang kota dari aspek simbolik, fungsi arsitektural, dan budaya. Dalam "Space and place; Humanistic perspective", ahli kajian geografi budaya, Yi-Fu Tuan membagi ruang ke dalam dua kategori: public symbols (simbol publik) dan fields of care (bidang yang melibatkan emosi) ${ }^{1}$. Public symbols adalah simbol yang dibentuk dari lokasi atau benda dalam ruang publik, seperti monumen, gedung, kota dan karya seni, yang berfungsi menjadi pusat makna, nilai, dan kepentingan tertentu (Yi-Fu Tuan (1974) dalam Baldwin et al. 2004: 142). Ruang-ruang tersebut dibangun dan diciptakan secara sengaja dan diberikan fungsi sebagai pusat makna yang mewakili nilai-nilai yang dimiliki sebuah masyarakat. Public symbols dibedakan dari fields of care, yaitu ruang-ruang yang bermakna akibat adanya keterkaitan emosional. Ruang-ruang yang menimbulkan rasa keakraban, kedekatan, dan afeksi. Tempat-tempat seperti rumah, taman yang alami, sudut jalan perumahan, pasar, dan kota kecil dengan aspek akrab dan menyentuh dapat dikategorikan ke dalam fields of care. Kontras antara yang besar, megah, kekar dengan kecil, akrab, dan lembut juga tercermin dalam pendapat Susan Saegert dalam "Masculine cities and feminine suburbs. Saegert (1980 dalam Monk 1984: 28) mempertentangkan wilayah suburban yang feminin dengan kota besar yang maskulin dengan sifat-sifat khas "aggressive, assertive, definers of important world events, intellectual, powerful, active, [...] dangerous".

Pandangan Tuan dan Saegert mengimplikasikan adanya oposisi biner maskulin-feminin. Kategori public symbols dengan ciri-ciri yang dimilikinya diasosiasikan sebagai ruang-ruang yang maskulin. Sebaliknya, fields of care yang melibatkan emosi dilihat sebagai ruang yang menunjukkan kekhasan perempuan. Perlu dicatat bahwa kategori maskulin dan feminin di sini tidak lepas dari konstruksi sosial yang patriarkis, karena ruang publik masih diasosiasikan dengan wilayah laki-laki, sedangkan ruang yang bernuansa emotif diasosiasikan dengan perempuan.

Karena terpengaruh kuat oleh nilai dan norma patriarki, posisi perempuan dalam ruang kota sering dilihat berada marjinal dan tidak menguntungkan. Feminis Prancis, Hélène Cixous (1976: 49), dalam "Castration or decapitation?" bahkan menganalogikan posisi perempuan di dalam kota seperti posisi sphinx, yaitu representasi figur perempuan yang mengawasi (watch-bitch) dan diletakkan di luar kota, bukan di kota di pusat makna yang diatur oleh hukum laki-laki, "That is to say, she is outside the city, at the edge of the city - the city is man, ruled by masculine law" (dalam Sizemore 1992: 90). Menurut Jacques Lacan (1973) kota adalah milik laki-laki dan untuk laki-laki dengan adanya

1 Untuk seterusnya dalam artikel ini dipakai istilah public symbols dan fields of care. 
the law of the father ${ }^{2}$ sehingga posisi perempuan menjadi marjinal. Sementara itu, Julia Kristeva (1986), filsuf feminis Bulgaria-Perancis, melihat perempuan sebagai golongan yang terkastrasi yang tidak memiliki peran penuh dalam budaya yang mendominasi kota (dalam Baldwin et al. 2004). Dalam analisis teks sastra yang dilakukannya, Kristeva mencermati bagaimana perempuan dalam ruang urban seringkali diposisikan bukan sebagai tokoh utama tetapi sebagai tokoh pembantu dengan peran samping atau pelengkap.

Profesor studi feminisme, Rita Felski (1995), melihat sistematisasi, rasionalisasi, produktivitas, dan represi sebagai kualitas maskulin yang mendominasi modernitas dan kehidupan kota. Hasilnya, yang disebut feminin dalam ranah kota adalah sifat pasif, hedonistik, dan natural, atau karakterkarakter yang oleh dominasi patriarki dikukuhkan sebagai sifat stereotipikal perempuan (dalam Baldwin et al. 2004: 189).

Menyikapi penggambaran pengalaman tokoh perempuan dalam ruang kota di Lost in translation dan The good girl, analisis ini akan memanfaatkan persepsi mengenai ruang kota yang sejalan dengan pendapat Tuan dan Saegert dikatakan stereotipikal maskulin dengan memperhatikan posisi perempuan terhadap objek-objek lain yang berada di ruang itu. Artikel ini akan menggunakan ancangan femininitas Julia Kristeva untuk membahas relasi antara tokoh-tokoh perempuan dengan objek-objek di sekitarnya dalam ruang kota. Menurut Kristeva, femininitas adalah "apa yang dimarjinalkan oleh symbolic order yang patriarki" ${ }^{3}$ (Kristeva dalam Moi 1991: 126). ${ }^{4}$ Dengan kata lain, femininitas diasosiasikan sebagai sebuah "posisi" yang marjinal, sementara patriarki adalah kuasa yang memarjinalkan. Dengan marjinalisasi itu oposisi feminin versus maskulin pun menjadi sesuatu yang tidak statis. Oleh karena femininitas didasarkan pada posisi (dan bukan esensi), maka femininitas memiliki celah ruang untuk bergeser dan bangkit dari posisi marjinal.

Dalam "Feminism and geography" (1993), Gillian Rose mengungkapkan bahwa untuk bertahan di dalam ruang kota, perempuan menciptakan suatu ruang lagi yang pada umumnya sering bersifat khayalan (imaginary) (dalam Mountford 2001: 56). Ruang ini disebut oleh Rose sebagai ruang ketiga, suatu ruang yang dapat diinterpretasikan sebagai ruang yang berada di luar oposisi maskulin versus feminin. Dalam ruang ini perempuan menemukan kebebasannya dari nilai dan aturan kota maskulin yang menjadikan posisinya marjinal. Ruang ini menjadi solusi tempat untuk keluar dari lingkungan dengan hukum laki-laki.

$2 \quad$ Menurut J. Lacan (1973) The law of the father adalah hukum ayah yang menopang symbolic order - sebuah ranah yang dimasuki seorang anak ketika ia mulai kehilangan keterikatan dengan ibu. Anak mulai mengenal bahwa kepada ayahlah ia harus mengidentifikasikan diri, dan pada peraturan sang ayahlah ia harus patuh. Feminisme melihat symbolic order sebagai sebuah ruang yang menyiratkan kedewasaan, sifat normatif, patriarki, rasional, dan didominasi oleh phallus (Watkins 2001: 99).

3 Diterjemahan oleh penulis dari teks asli yang menyebut femininitas sebagai "that which is marginalised by the patriarchal symbolic order" (Kristeva dikutip oleh Moi 1991: 126).

4 Lihat pula “Femininity as marginality" dalam Moi (1985: 163-167). 


\section{LOST IN TRANSLATION}

\section{Keterpenjaraan Charlotte}

Salah satu adegan yang menjadi ikon film Lost in translation adalah ketika Charlotte, tokoh perempuannya, berdiri di persimpangan jalan ramai Tokyo. Lingkungan tempatnya berdiri merupakan ruang yang dipenuhi gedung pencakar langit dan manusia. Charlotte, memandang ke salah satu gedung tinggi (Gambar 1b), dan melihat seekor dinosaurus hologram raksasa yang sedang berjalan menempel pada dinding gedung itu (Gambar 1a).

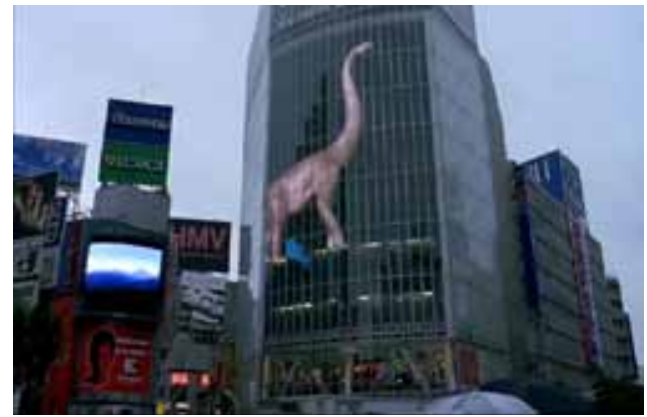

Gambar 1a. Hologram dinosaurus di simpang jalan di Tokyo.

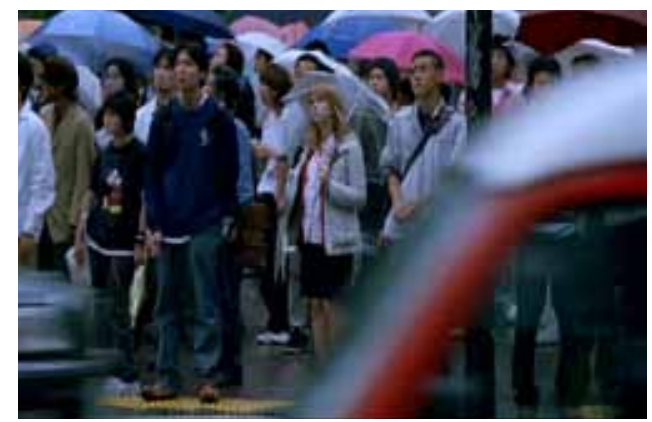

Gambar 1b. Charlotte memandang gedung.

Binatang purbakala yang ditampilkan secara artifisial dan masif ini seakan mewakili ruang Tokyo yang besar dan metropolitan. Namun, kemunculan dinosaurus ini di tengah kota besar Tokyo yang sarat kultur pop dan digital ini juga tampak tidak wajar; suatu konsep purbakala dipertentangkan dengan konsep modern. Dari gambar dinosaurus, kamera kemudian beralih pada Charlotte yang tampak kecil di tengah hiruk-pikuk kota besar Tokyo, di antara orang-orang ia memandang jauh ke atas. Pengambilan gambar lowangle-long-shot yang memperlihatkan arah pandang Charlotte, menunjukkan relasi kuasa dalam posisi besar (ruang kota yang besar dan mendominasi) versus kecil (Charlotte yang kecil dan tidak berarti).

Persimpangan jalan dan gedung-gedung tidak hanya menggambarkan modernitas Tokyo, namun juga merepresentasikan apa yang disebut oleh Yi-Fu Tuan sebagai public symbols yang memperlihatkan tanda-tanda umum sebagai sebuah ruang yang maskulin. Gedung pencakar langit adalah ikon kota metropolitan yang menurut Lefebvre (1984) menyerupai penis, "Vertikalitas arogan yang dimiliki gedung-gedung pencakar langit, terutama gedung-gedung milik umum dan negara, mengenalkan sebuah elemen phallic, atau lebih tepatnya phallocratic, ke dalam lingkup visual" ${ }^{5}$ (Lefebvre dalam Mountford 2001: 49-50). Vertikalitas yang menjulang pada gedung pencakar langit menyimbolkan otoritas dan arogansi; suatu karakter yang dikatakan khas maskulin. Dari wujud gedung yang tinggi, kekar, dan mendominasi

Terjemahan penulis untuk "The arrogant verticality of skyscrapers, and especially of public and state buildings, introduces a phallic or more precisely a phallocratic element into the visual realm". 
ini terpancar otoritas dan kuasa atas mereka yang melihatnya (termasuk di antaranya Charlotte). Lefebvre menambahkan, "Garis vertikal dan ukuran tinggi yang luar biasa selalu menjadi ekspresi spasial yang berarti potensi kekuatan besar"6 $^{\prime \prime}$ (dalam Mountford 2001: 49). Ruang-ruang maskulin hadir di sekeliling Charlotte bahkan hingga di hotel yang ditinggalinya. Berangkat dari persepsi Rita Felski mengenai modernitas yang menjadi ranah maskulin, hotel tempat tinggal Charlotte yang berteknologi tinggi dan bernuansa minimalis memiliki fungsi simbolik seakan memenjarakan Charlotte. Adegan Charlotte berjalan di tengah lorong hotel menunjukkan bagaimana Charlotte berada dalam ruang dengan lingkungan yang bernada kaku, geometris, dan maskulin.

Ruang hotel menjadi representasi bangunan dengan gaya arsitektur serba canggih dan monumental, termasuk pada kategori public symbols atau ruang kota yang menurut pandangan Yi-Fu Tuan, "publik dan tidak personal"7 (Tuan 1988: 318). Suasana asing dan sepi yang terbangun dari detail minimalis dalam ruang-ruang hotel dianggap menjadi karakter yang tipikal milik pria. Hal ini diperkuat oleh pendapat Jessica Benjamin (1986), seorang tokoh feminis psikoanalisis. Menurut Benjamin, psikoanalisis Freudian dan neo-Freudian menggarisbawahi perpisahan anak lelaki dari ibunya sehingga menyebabkan timbulnya ciri individualistis dan alienasi yang mengingkari komunalitas, serta perpisahan atau diskoneksi antarindividu (dalam Sizemore 1992: 92). Walau berfungsi sebagai tempat tinggal, hotel tempat Charlotte menginap lebih terasa sebagai ruang formal dan pembangun sifat individual khas maskulinitas.

Posisi Charlotte dalam ruang hotel dan kota Tokyo adalah sebagai pelengkap saja. Sementara sang suami sibuk bekerja di luar, Charlotte hadir dalam ruang-ruang tersebut sebagai tokoh sampingan. Dalam konteks ini ia menjadi pelengkap baik untuk suami maupun untuk ruang kota Tokyo, seperti tersirat dalam pernyataannya, "My husband is a photographer, so he's here working. I wasn't doing anything, so I come along, also to meet some friends". Gurauan Bob untuk kabur dari hotel dan kota yang bagai penjara juga hanya bisa dijawab Charlotte dengan senyum. Ia berkata "I' $m$ in. Let me just pack my stuff", lalu berjalan kembali ke meja makan di mana sang suami sedang duduk asyik bercerita dengan teman-temannya. Tindakan Charlotte ini menyiratkan otoritas ruang hotel dan ruang kota Tokyo yang maskulin dan situasi itu secara spesifik didominasi oleh posisi sang suami. Di bawah otoritas itu pula, Charlotte merasa terkondisi untuk tetap berada di dalamnya.

Gambaran keresahan Charlotte yang terasa terpenjara dalam ruang-ruang maskulin ditunjukkan oleh adegan memandang ke luar jendela kamar (baik di kamar hotel maupun di ruang lain seperti di dalam taksi dan kereta api). Jendela secara simbolis merupakan perantara antara "dalam" dan "luar", atau pembatas antara keterkurungan dan kebebasan. Adegan yang muncul secara berulang-ulang ini mengisyaratkan adanya tokoh yang mendambakan apa

$6 \quad$ Terjemahan penulis untuk "Verticality and great height have ever been the spatial expression of potentially violent power".

7 Diterjemahkan oleh penulis. 
yang ada di luar "penjara".

Karena terkondisi untuk tetap tinggal di hotel, Charlotte ditunjukkan melakukan sejumlah usaha untuk bertahan di ruang maskulin, salah satunya dengan mengelilingi diri di antara hal-hal yang menandai femininitas, misalnya bunga dengan warna merah muda yang dipasangnya untuk menghiasi ruang hotel (Gambar 2).

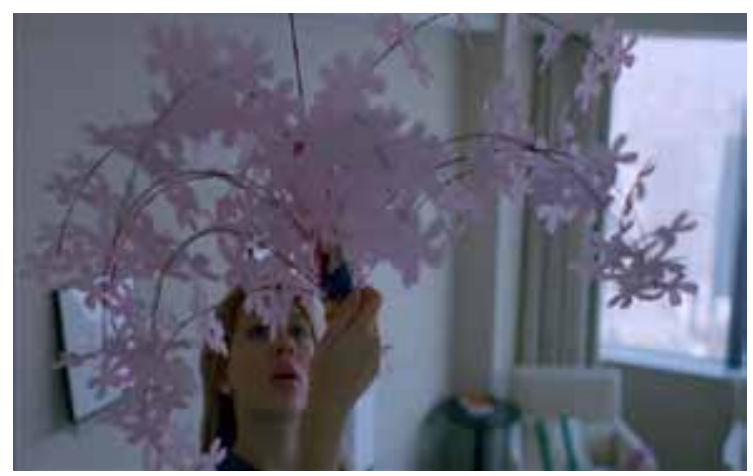

Gambar 2. Charlotte menggantung hiasan bunga (berwarna merah muda).

Bentuk ekspresi feminin lain juga nampak lewat Charlotte yang menunggu suaminya pulang dengan merajut dan memakai kosmetik (yang dari raut mukanya tampak dilakukan secara terpaksa). Charlotte juga sempat menemui ruang kelas merangkai ikebana. Kegiatan merangkai bunga ini yang dikombinasikan dengan minum teh dan menari tradisional menjadi bagian budaya perempuan Jepang, yang juga menyimbolkan keperempuanan. Bunga yang beberapa kali hadir dalam gambar bersama dengan Charlotte adalah bunga berwarna merah muda, yang menandai khas femininitas dengan asosiasi kelembutan pada perempuan. Aspek-aspek keperempuanan yang ditampilkan dalam beberapa adegan ini dapat diinterpretasikan sebagai upaya Charlotte bertahan di dalam ruang yang ditandai oleh dominasi maskulinitas. Ruang hotel yang lebih menjadi "milik" suami dengan segala upaya Charlotte dicoba untuk dirasakan pula sebagai miliknya.

Dalam "ruang" kota Tokyo, pencarian ruang untuk dirinya dilakukan Charlotte dengan mengunjungi tempat-tempat wisata di Jepang seperti kuil dan taman-taman alami. Tempat-tempat seperti inilah yang menurut Tuan tergolong dalam fields of care, tempat yang menyiratkan ungkapan emosi karena melibatkan perasaan, suatu sifat yang dipandang mencirikan perempuan. Di tempat-tempat ini Charlotte juga menemukan sisi ketradisionalan Jepang, yang tidak ditemuinya ketika ia berada di tengah jalan-jalan sibuk dan gedung pencakar langit Tokyo. Dilihatnya sepasang pengantin berpakaian tradisional dengan pengantin laki-laki memayungi pengantin perempuan - sesuatu yang didambakan Charlotte dalam hubungannya dengan suami. Menyaksikan pemandangan tersebut menandai kehampaan dan kesendirian yang dirasa oleh Charlotte. 
Pelbagai adegan yang menunjukkan hal-hal yang dialami atau dilakukan oleh perempuan (seperti kegiatan ikebana dan kesan perhatian dan perlindungan yang dialami oleh pengantin perempuan Jepang) dirasakan oleh Charlotte bukan untuk dirinya. Ia hanya sebagai "penonton" dan bahkan di ruang-ruang yang "feminin" ia tetap merasa terpenjara. Ia mengeluhkan hal itu pada seorang teman sambil menangis, "I went to this shrine today [...] and I didn't feel anything, you know? I even tried ikebana [...] I just - I don't know who I married". Perkataan Charlotte ini mengekspresikan ungkapan keterpenjaraannya di ruang yang baginya terasa hampa dengan suami yang juga semakin asing di matanya.

\section{Ruang Ketiga Charlotte}

Dalam upayanya bertahan di ruang kota yang dirasanya memenjarakan, Charlotte membangun ruang ketiga untuk dirinya. Dalam upayanya ini ia melibatkan tokoh laki-laki lain, Bob.

Tak jauh berbeda dengan Charlotte, Bob juga menyimpan permasalahan dengan pernikahannya. Bob berada di Jepang untuk melakukan pekerjaan yang juga tidak disukainya sambil dibayang-bayangi figur istrinya di Amerika dan hubungan dingin mereka. Charlotte dan Bob mulai menyusuri sejumlah tempat terpencil di balik lorong gedung-gedung Tokyo untuk bersenangsenang. Ruangan yang dikunjungi oleh keduanya adalah ruang-ruang berskala kecil yang terletak di sudut-sudut kecil di dalam kota; gambaran kontras dengan gedung pencakar langit yang masif dan hiruk pikuk di kota besar Tokyo. Ruang ketiga lain yang memberikan kenyamanan ditemukan oleh Charlotte di dalam sebuah gedung tinggi, tempat Charlotte dan Bob berkaraoke. Dalam adegan ini Charlotte ditampilkan memakai rambut palsu warna merah muda, suatu atribut warna yang mencirikan keperempuanan.

Pengambilan gambar Charlotte dan Bob (dengan kepala Charlotte di bahu Bob) berawal dari arah samping dan kemudian beralih dari arah depan, merepresentasikan pengisian makna pada ruang yang seakan hanya milik kedua tokoh itu. Sekalipun ruangan tersebut sempit, kontras dengan ruang hotel ataupun ruang-ruang kota Tokyo yang masif, Charlotte dengan bantuan Bob mampu membangun ruang untuk dirinya agar membebaskan diri dari rasa terpenjara

Ruang ketiga lain tercipta di dalam taksi. Pengambilan gambar dimulai menyorot raut muka Charlotte yang sedang memandang ke luar jendela taksi. Gambar kemudian bergerak menunjukkan arah tatapan Charlotte ke Bob. Charlotte terlihat tersenyum - sebuah ekspresi yang menunjukkan lagi keberhasilan Charlotte keluar dari keterpenjaraan.

Ruang ketiga yang dibangun Charlotte terlihat tanpa bias gender ataupun oposisi maskulin-feminin. Di ruang ketiga itu tokoh laki-laki (Bob) dan perempuan (Charlotte) sama-sama mendapatkan manfaat. Relasi yang seimbang di antara keduanya tergambarkan dengan baik dengan mengamati adegan ketika keduanya tertidur di kamar hotel. Sejenak, di ranjang Bob menyentuh kaki Charlotte tetapi tidak terjadi hubungan seksual. Kehangatan 
dan kenyamanan dikemukakan di sini untuk menunjukkan perasaan yang sama dari kedua tokoh. Gambar ini dapat diinterpretasikan juga sebagai keberhasilan penciptaan ruang ketiga oleh kedua tokoh sebagai tempat untuk keluar dari rasa tertekan dan terperangkap.

Ruang ketiga yang pada umumnya tercipta dan diciptakan untuk sementara karena menjadi alternatif tempat pelarian sejenak saja, pada akhirnya memang tidak menjanjikan apa-apa. Di akhir cerita, kenyamanan dan kebebasan yang diperoleh dalam ruang itu pun menghilang kembali. Charlotte kembali memasuki ruang yang terasa memenjarakan dan menempatkannya pada posisi marjinal, sementara tokoh tokoh laki-laki, Bob, meninggalkan kota Tokyo untuk kembali ke Amerika. Gambar menunjukkan pada pertemuan akhir mereka, Bob membisikkan sesuatu kepada Charlotte tetapi suara bisikan itu hilang tertindih oleh suara latar lagu dan hiruk pikuk Tokyo. Hal ini menandai kembalinya Charlotte ke ruang yang nyata yang menempatkannya kembali pada posisi yang tidak berarti. Tanda ini juga ditegaskan dengan susulan gambar yang memperlihatkan Charlotte berada di tengah keramaian Jepang, kembali teralienasi dan merasa terpenjara seperti sediakala.

\section{THE GOOD GIRL}

\section{KETERPENJARAAN JUSTINE}

"I saw in your eyes you hate the world. I hate it too", demikian kata Justine kepada Holden. Dunia yang diucapkan Justine merepresentasikan dunia secara luas (kota tempat tinggalnya) sekaligus pula dunia dalam arti sempit (Hypermart Retail Rodeo tempat keduanya bekerja). Kebencian Justine pada kota yang mengungkungnya dipertegas oleh bagian awal adegan: Justine sedang mengoles lipstik dengan sikap malas dan suaranya terdengar melatari gambar (lihat gambar 3),

"As a girl you see the world like a giant candy store filled with sweet candy. But one day you look around, you see a prison and you're on a death row. Something's locking you up".

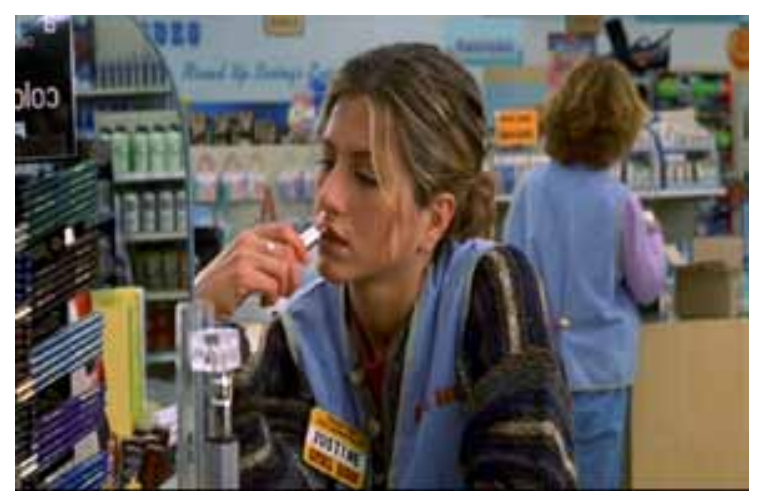

Gambar 3. Justine mengoles lipstik dengan sikap malas. 
Simbolisasi ditemukan dalam tuturan itu. Dunia yang dulu dipandangnya bak toko permen raksasa dengan isinya yang memberikan kesenangan ternyata pada suatu hari dilihatnya sebagai suatu penjara yang tidak memungkinkannya keluar hingga ajal. Rasa keterpenjaraan demikianlah yang dirasa Justine dalam kehidupannya di kota tempat tinggalnya dan rutinitas pekerjaannya di Hypermart. Seperti Charlotte dalam Lost in translations, Juistine pun hidup dalam lingkungan kota yang modern meskipun bukan kota metropolitan seperti Tokyo. Suatu ruang kota yang dilengkapi dengan bangunan gedung Hypermart. Hypermart yang merepresentasikan kapitalisme dapat dikategorikan dalam konsep yang dikatakan oleh Felski menunjukkan stereotip maskulin (dalam Baldwin et al. 2004: 189). Giles dan Middleton (1999) berpendapat bahwa supermarket merupakan tempat interaksi individu dengan kekuatan komersialitas. Bersama dengan kekuatan ini muncul pula upaya memanfaatkan karakter maskulin untuk kebutuhan promosi. Rodeo dan laso merupakan atribut yang jelas memperlihatkan kemachoan. Tanda kemaskulinan ini dipakai sebagai maskot Hypermart di kota tempat tinggal Justine. Gambar rodeo dengan laso inilah yang menghiasi atas pintu masuk Hypermart. Lambang kemaskulinan inilah pula yang setiap hari menyambut kedatangan Justine di tempat kerjanya. Gerai kosmetik tempat Justine bekerja terletak tepat di tengah ruang yang terbuka sehingga tidak memungkinkan adanya privasi (lihat Gambar 4).

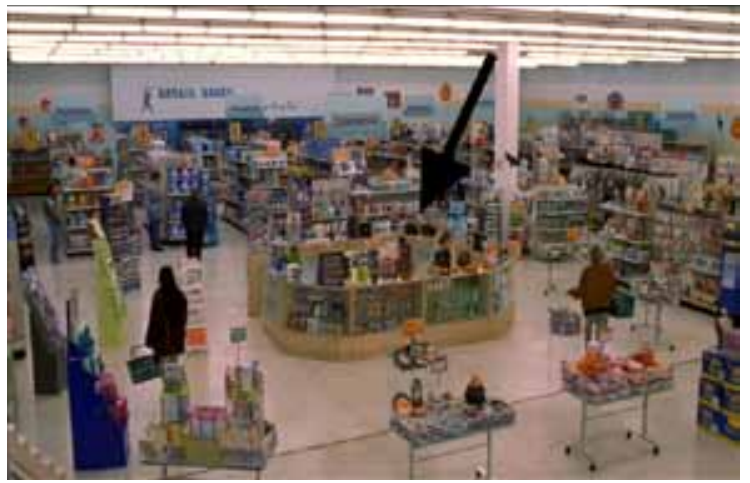

Gambar 4. Gerai kosmetika di tengah ruang terbuka.

Dengan penempatan gerai kosmetik untuk keperluan perempuan di tengah ruang yang terbuka ini seakan mengungkapkan pula maksud Hypermart menjadikan gerai perempuan itu sebagai objek penarik perhatian yang menghiasi kemegahan ruang keseluruhannya yang maskulin. Justine yang pekerjaannya mengurusi gerai kosmetik sangat membenci gerainya dan sesungguhnya ia pun tidak suka memakai kosmetik. Sikap Justine dapat dilihat sebagai penolakan terhadap stereotip perempuan yang coba dilekatkan oleh bisnis kapitalis Hypermart itu. Tokoh Justine dikontraskan dengan Gwen, karyawan paruh baya di gerai yang sama dan yang selalu menyarankan Justine untuk memakai kosmetik agar terlihat menarik dan menyenangkan bagi suaminya. Gwen yang 
periang adalah tipikal wanita paruh baya Amerika produk mistik femininitas (feminine mystique) yang menyebabkan lahirnya gambaran "motherhood and apple pie" (bahwa tugas perempuan adalah menyambut dan melayani suami setelah ia pulang kerja). ${ }^{8}$ Justine tidak menyukai Gwen dengan sikapnya yang selalu tampak bahagia tanpa alasan. Oposisi Gwen dan Justine menunjukkan pula adanya oposisi antara pengikut nilai dan aturan yang standar (yang menjadi panutan umum dalam masyarakat) versus penentangnya (yang berkeinginan keluar dari nilai dan aturan standar itu). Gwen adalah sosok yang memenuhi harapan nilai dan aturan standar itu; Gwen mencintai pekerjaannya di gerai kosmetik itu dan tampak selalu bahagia. Gambaran ideal yang tidak saja diharapkan tetapi juga dituntut dari sosok perempuan. Gambaran ini tidak dipenuhi oleh Justine. Dengan nilai dan aturan itu Justine justru merasa terpenjara.

\section{RuANG KETIGA JUSTINE}

Di dalam relasi kuasa dengan adanya dominasi maka selalu ada potensi bagi mereka yang ditekan untuk melakukan perlawanan, demikian halnya dalam situasi yang dihadapi oleh Justine. Bentuk perlawanan yang dilakukan oleh Justine adalah dengan menciptakan 'ruang ketiga', suatu ruang yang memberikan suatu ketahanan dalam menghadapi sekelilingnya. Ruang itu tercipta dengan langkahnya untuk berselingkuh dengan Holden. Justine mengelabui suaminya dan mengadakan pertemuan-pertemuan rahasia dengan Holden di pelbagai sudut tersembunyi di dalam gudang Hypermart. Tidak saja sudut gudang tetapi juga mobil pun ikut menjadi bagian dari ruang ketiga yang dimasuki oleh Justine dengan perselingkuhannya ini.

Seperti Justine, tokoh Holden juga mendambakan kebebasan. Di awal cerita, Holden digambarkan sebagai sosok muda yang romantis, ekspresif, dan dengan terus terang mengungkapkan cintanya pada Justine. Konflik pecah ketika perselingkuhan Justine diketahui oleh Bubba, sahabat Phil atau sang suami. Justine diperas dan terpaksa berhubungan seksual dengan Bubba demi menyembunyikan perselingkuhannya dari Phil. Hingga akhir cerita, anak yang kemudian dikandung Justine tak jelas siapa ayah biologisnya, namun ia meyakinkan baik pada Phil maupun pada Holden bahwa anak yang dikandungnya adalah anak mereka. Holden kemudian menawarkan Justine solusi untuk permasalahannya, yaitu pilihan untuk pergi bersamanya meninggalkan kota mereka.

Memasuki bagian akhir cerita, tokoh Holden digambarkan sebagai tokoh yang sangat terobsesi pada Justine sehingga mampu menyakiti diri sendiri demi menunjukkan cintanya kepada Justine. Ia juga berubah menjadi seorang pencuri demi mendapatkan uang untuk membahagiakan Justine. Tokoh lakilaki di sekitarnya dirasakan Justine merupakan tokoh dengan pribadi yang mengecewakan dan tidak dapat diandalkan dalam upayanya mendapatkan

$8 \quad$ Betty Friedan dalam The feminine mystique (1963) mengungkapkan mistik keperempuanan, yaitu bahwa untuk menjadi perempuan yang sempurna adalah melalui pernikahan, peran sebagai ibu, dan domestisitas (dibahas dalam Watkins 2001). 
kebahagiaan. Kebohongan yang diberitahukan pada Holden dan Phil menjadi solusi Justine untuk tetap bertahan dengan memanfaatkan keadaan. Phil yang terobsesi untuk memenuhi panggilan tugasnya sebagai ayah dan laki-laki dalam keluarga sesuai konstruksi patriarki, membuka peluang bagi Justine. Ruang ketiga yang tercipta dengan perselingkuhan itu memang lenyap tetapi dalam posisi ini sekarang kendali dominasi ada di tangan Justine meskipun dengan kebohongan.

Konstruksi gender masyarakat Barat menunjukkan superioritas lelaki dan inferioritas perempuan melalui hubungan subordinasi budaya atau peradaban atas alam (Balwin et al. 2004). ${ }^{9}$ Oposisi yang sama nampak digunakan dalam film lewat penggambaran ruang-ruang alam yang dipertentangkan dengan ruang-ruang dalam kota dan Hypemart. Seperti halnya dengan Charlotte dalam Lost in translation, Justine dalam The good girl seringkali melihat ke luar jendela kamar, seakan mendambakan apa yang ada di luar ruang, yaitu alam. ${ }^{10}$ Ruang tempat ia berada diasosiasikan sebagai ruang yang mengungkung dan memenjarakannya sebagai perempuan. Di luar ruang adalah alam yang seakan menjanjikan kebebasan. Dalam hal ini dapat diinterpretasikan pula adanya oposisi maskulin-feminin: 'ruang' dilihat sebagai penjara dengan otoritas maskulin dan 'di luar ruang' adalah alam yang feminin dan diimpikan sebagai tempat yang sejiwa dengannya yang dapat mengeluarkannya dari tekanan. Dalam konteks yang lebih luas lagi, ruang kota pun dipandang sebagai penjara karena nilai dan aturan maskulin yang tampak menguasai lingkungan sosial urban.

Pepohonan yang bergerak karena tiupan angin keras di halaman belakang turut menandakan gejolak hati Justine yang merasa terperangkap dan terpenjara oleh ruang. Gambar dalam adegan ini juga menandai adanya pergantian alur cerita. Di bagian akhir, Justine dihadapkan pada pilihan: memilih Holden yang dengan uang curian dari Hypermart sudah siap melarikan diri bersamanya ke luar kota atau tetap tinggal di kota bersama suaminya, Phil, dengan bayi dalam kandungan sebagai buah pengkhianatannya. Keadaan yang dihadapi Justine digambarkan oleh film dalam simbolisasi: (1) gerai kosmetik dan Hypermart yang dijaga oleh para lelaki petugas keamanan dan (2) jalan antarkota dan alam luas yang tak berujung. Yang pertama menyiratkan "dominasi dan kungkungan" dan yang kedua memperlihatkan harapan untuk bebas dari dominasi dan kungkungan itu. Dalam penyajian gambar ini terdengar suara latar dari Justine yang berkata:

9 Dalam pembahasan, Baldwin et al. mensintesiskan pendapat Moore (1993), Ortner (1974), dan Strathern (1981) yang membahas asosiasi laki-laki dengan budaya (culture) dan perempuan dengan alam (nature). Hal ini sejalan dengan konstruksi lain, yaitu bahwa laki-laki menguasai wilayah publik dan perempuan diposisikan pada wilayah privat (Baldwin et al. 2004: 120).

10 Film berkali-kali memperlihatkan gambar ketika Justine pada malam hari berbaring melihat ke luar jendela ke halaman belakang rumah dengan raut muka sendu. 
How it all came down to this onlythe devil knows [...] I close my eyes try to peer into the future. On my left, I saw days upon days of lipstick and ticking clocks, dirty looks, and quiet whisperings, and dirty secrets that just won't ever die away. And on my right, what I could picture, the blue sky and dessert earth stretching out into the eerie infinity of beautiful never ending nothing.

Mengikuti cara pandang Saegert, Hypermart yang ada dalam bayangan Justine kerap dijaga sekolompok pasukan pengaman sehingga dapat dianggap sebagai wujud yang menunjukkan maskulinitas. Wujud itu sesuai dengan apa yang disebut oleh Saegert sebagai otoritas maskulin yang "agresif dan berkuasa" (lihat Saegert dalam Monk 1984: 28). Penjagaan juga dapat diartikan sebagai pengamanan demi supremasi hukum maskulin (lihat Cixous dalam Sizemore 1992: 90). Pencitraan Hypermart yang dimaknai sebagai pencitraan maskulin kemudian dipertentangkan dengan pencitraan feminin yang digambarkan melalui gambar alam, bumi tanpa batas, dan langit biru. Pencitraan feminin seperti ini sesuai pula dengan pandangan Yi-Fu Tuan tentang fields of care. Penyajian gambar yang memperlihatkan keadaan di mana Justine harus membuat pilihan, dapat dinterpretasikan sebagai penciptaan "ruang khayalan" sesuai pendapat Gillian Rose (1993), yaitu sebuah ruang imajiner yang memperoleh pemaknaan melalui relasinya dengan ruang yang nyata (dalam Mountford 2001: 56).

Ruang alam sebagai ruang ketiga yang dalam angan-angan menjanjikan kebebasan (akhir yang bahagia dan perjalanannya bersama Holden ke luar kota menjauhi Hypermart) dipandang oleh Justine sebagai janji kebebasan yang kosong, misterius, dan menakutkan. Adegan dalam film turut mendukung dengan menunjukkan Justine yang saat itu harus membuat pilihan sedang berada di dalam mobil sementara di luar hujan mengguyur deras, merefleksikan kemelut hatinya dalam mencari jalan keluar yang tak mudah. Kebebasan yang didambakannya pada akhirnya hanya tinggal khayalan. Justine menjatuhkan pilihan untuk tetap tinggal bersama Phil meskipun dengan konsekuensi bahwa ia tetap hidup dalam kebohongan, rahasia, dan menjadi pergunjingan masyarakat sekelilingnya.

Pilihan Justine (kembali ke suami meskipun untuk itu tetap merasa terpenjara) sebagai sebuah pilihan yang logis seakan sesuai dengan tuntutan nilai dan aturan masyarakat yang berlaku. Dalam film, pilihan itu tampak ditegaskan sebagai pilihan yang tepat. Hal itu didukung dengan penggambaran Holden yang depresif di akhir film yang kemudian mengakhiri nyawanya sendiri dan penggambaran tokoh Phil yang justru menarik simpati. Ketika perselingkuhan Justine terungkap, Phil berkata: "I just got to escape, you know. Have you ever felt like that? Like you want to escape?" Dalam konteks ini Phil yang pada awal film digambarkan sebagai pemegang kendali dalam rumah tangga (sebagai kepala keluarga), tampak menempatkan diri sejajar dengan Justine. Keduanya digambarkan memiliki keinginan yang sama untuk keluar dari permasalahan meskipun alasan masalah pada kedua orang ini berbeda (kota merupakan perangkap bagi Justine, dan bagi Phil tugasnya sebagai kepala keluarga dianggapnya sebagai kekangan). Nilai dan aturan yang berlaku dalam 
masyarakat yang banyak dianggap bersifat patriarkis, pada akhirnya juga menjadi penentu moral tidak saja pada perempuan tetapi juga pada laki-laki.

Adegan kemudian beralih pada sebuah Hypermart yang baru buka di pagi harinya. Lampu menyala satu per satu dan kamera berfokus pada gerai kosmetik dan Hypermart dalam situasi seperti biasanya. Adegan ini seakan menyimbolisasikan roda hidup Justine dan rutinitas Hypermart serta kota yang akan terus berjalan. Suatu pilihan yang diambil Justine dengan konsekuensinya pada akhirnya menjanjikan pula suatu harmoni. Justine digambarkan sedang berada di kamar sambil memandang ke halaman (sementara angin tidak lagi sekencang dahulu). Phil menghampirinya dengan seorang bayi di pelukan. Justine tersenyum. Upaya keluar dari keterpenjaraan oleh tokoh perempuan tidak dicapai tetapi, dalam masyarakat dengan nilai dan aturan yang cenderung berorientasi patriarki, keputusan untuk kompromi, kembali menjadi istri dan tetap hidup di kotanya tampak sebagai satu-satunya pilihan.

\section{PENUTUP}

Di balik kisah percintaan yang diangkatnya, Lost in translation dan The good girl menggambarkan ruang kota yang megah dan maskulin dengan sosok perempuan yang tampak kecil dan tidak berarti sebagai akibat posisinya yang terpinggirkan. Kedua film itu memiliki kesamaan, yaitu memperlihatkan perempuan sebagai objek yang terperangkap di tengah kemegahan perkotaan dan dominasi maskulin dalam struktur masyarakat sosial yang patriarki.

Bagi Charlotte, tokoh perempuan dalam Lost in translation, kota metropolitan dan hotel merupakan ruang yang dirasakannya memenjarakannya, sementara bagi Justine, tokoh perempuan dalam The good girl, kota tempat tinggalnya dan Hypermart tempat kerjanya yang membuatnya merasa terpenjara. Hubungan dengan suami yang dingin dan rutinitas dalam roda kehidupan mereka menimbulkan kehampaan yang dalam. Kota dan bangunan gedung, menurut Yi-Fu Tuan, adalah simbol-simbol umum yang memperlihatkan ciri maskulin. Dalam kedua film itu diperlihatkan relasi kuasa melalui oposisi maskulin/besar (kota, gedung pencakar langit, gedung Hypermart) versus feminin/kecil (Charlotte, Justine). Upaya dari tokoh perempuan untuk keluar dari rasa keterpenjaraan ini menimbulkan terciptanya suatu ruang yang dirasa memberi kebebasan dan kebahagiaan. Namun, ruang yang tercipta tidaklah abadi. Pada film pertama keakraban dan kenyamanan yang dirasakan oleh Charlotte harus dilepaskan ketika Bob kembali ke negaranya. Kendali kuasa bukan berada di tangan Charlotte; Bob meninggalkannya dan ia kembali dalam ruang yang nyata, dalam kehidupannya semula. Pada film kedua kendali kuasa tampak berada dalam tangan Justine. Ialah yang memilih untuk kembali ke suaminya, dan Holden, teman berselingkuhnya, pada akhirnya justru mengakhiri hidupnya akibat pilihan Justine itu. Pilihan yang logis dan sesuai dengan moral yang ada karena sejalan dengan nilai dan aturan umum yang berlaku dalam masyarakat. Menyudahi perselingkuhan dan membangun 
keluarga. Suami Justine, Phil, dalam film juga digambarkan sebagai lakilaki yang merasa memiliki tanggung jawab sebagai ayah. Struktur patriarki diperlihatkan secara jelas dalam kedua film. Tuntutan dan harapan akan peran laki-laki dan perempuan sesuai nilai dan aturan patriarki terwujud. Ruang-ruang sosial urban yang ditampilkan dalam film dapat dimaknai tetap berbias patriarki.

\section{TEKS KAJIAN}

The good girl (2002; $93 \mathrm{~min})$. Sutradara: Miguel Arteta; Produser: Matthew Greenfield; Ditulis oleh: Mike White; Pemeran: Jennifer Aniston, Jake Gyllenhaal, John C. Reilly; Zooey Deschanel; Distribusi: Fox Searchlight Pictures; Tanggal peluncuran: 7 August 2002.

Lost in translation (2003; $102 \mathrm{~min})$. Sutradara: Sofia Coppola; Produser:

Ross Katz; Ditulis oleh: Sofia Coppol; Pemeran: Bill Murray, Scarlett Johansson; Musik: Brian Reitzell, Kevin Shields, Roger Joseph Manning, Jr. Air; Sinematografi: Lance Acord; Distribusi: Focus Features; Tanggal peluncuran: 3 Oktober 2003.

\section{DAFTAR PUSTAKa}

Baldwin, Elaine et al. 2004. Introducing cultural studies. Essex: Prentice Hall. Giles, Judy dan Tim Middleton. 1999. Studying culture; A practical introduction. Massachussets: Blackwell.

Lacan, Jacques. 1973. The fundamental concepts of psycho-analysis. New York: Norton and Company.

Moi, Toril. 1985. Sexual/textual politics; Feminist literary theory, London: Taylor and Francis.

Moi, Toril. 1991. "Feminist, female, feminine", di dalam: Catherine Belsey et al. (red.), The feminist reader; Essays in gender and the politics of literary criticism, hlm. 117-132. Cambridge, Massachusetts: Blackwell.

Monk, Janice. 1984. "Approaches to the study of women and landscape", Environmental Review Vol. 8 No. 1: 23-33. (Special Issue: Women and Environmental History (Spring, 1984); Forest History Society and American Society for Environmental History). (Http:// www.jstor.org/ stable/3984519), diakses pada 20/01/2009 05:33.

Mountford, Roxanne. 2001. "On gender and rhetorical space", Rhetoric Society Quarterly Vol. 31 No. 1 (Winter): 41-71. (Http://www.jstor.org/ stable/3886401), diakses pada 20/01/2009 05:26.

Sizemore, Christine W. 1992. "Masculine and feminine cities; Marge Piercy's 'Going down Fast' and 'Fly Away Home'", Frontiers; A Journal of Women Studies, Vol. 13 No. 1 (1992): 90-110. (Http://www.jstor.org/ stable/3346947), diakses pada 20/01/2009 05:34. 
Tuan, Yi-Fu. 1988. "The city as a moral universe", Geographical Review Vol. 78 No. 3 (July): 316-324. (Http://www.jstor.org/stable/215004), diakses pada 26/11/2008 00:23.

Watkins, Susan. 2001. Twentieth-century women novelists; Feminist theory into practice. Wales: Palgrave. 